\title{
Tradução especializada \\ Um mergulho nas especificidades do gênero jurídico
}

\author{
Rosane Mavignier Guedes*
}

\begin{abstract}
No interior de uma mesma linguagem jurídica, um termo pode estar revestido de diferentes significados. [...] Observa-se que certas palavras submetem-se a uma variação de sentidos segundo a instituição à qual se referem.
\end{abstract}

Sourioux e Lerat

\section{Introdução}

O amplo universo da tradução especializada inclui a tradução de textos jurídicos, sendo que este gênero já representa em si outro universo composto por diversas tipologias, cada uma com especificidades próprias traçadas para alcançar seu objetivo. Nesse conjunto, encontramos elementos linguísticos e não linguísticos que compõem as marcas funcionais e estilísticas do texto. Estas marcas induzem o leitor a identificar a que tipologia jurídica o discurso pertence. Ocorre que esses elementos podem não ser semelhantes nas duas línguas jurídicas trabalhadas pelo tradutor: do texto fonte e do texto alvo, como explica Malcolm Harvey (2009): "O tradutor jurídico depara-se constantemente com a diferença. Disponibilizar as noções de uma língua jurídica por meio de outra língua jurídica é confrontar dois sistemas, duas condutas, duas culturas jurídicas". Diante desse panorama, observamos que a atividade tradutória "pode" não se limitar a encontrar correspondentes linguísticos - terminológicos ou fraseológicos -, nem tampouco

\footnotetext{
* Advogada (OAB-RJ), especialista em Tradução de Língua Francesa (UERJ), mestre em Estudos Linguísticos Neolatinos - língua francesa (UFRJ), tendo trabalhado a linha de pesquisa Teoria e Práticas da Tradução e concluído a dissertação intitulada Os Meandros da Tradução Jurídica numa perspectiva franco-brasileira. Membro, na qualidade de pesquisadora da ABRAPT. Atualmente, leciona língua francesa no IPEL, PUC-Rio. Este artigo é inspirado no último capítulo da dissertação de Mestrado (UFRJ-2011).
} 
se limitar às marcas estilísticas. Como todas essas características são próprias de cada tipologia de textos jurídicos, Bocquet os categoriza em três modalidades: modo performativo, modo silogístico e modo descritivo, ensinando que cada uma tem sua respectiva aplicação.

Eis o esquema de base de textos jurídicos. Existem, então, três tipos de textos que podemos classificar de jurídicos: os textos normativos, os textos das decisões que aplicam as normas, e os textos que expõem o conteúdo das regras de direito, aqueles que chamamos, de forma geral, de doutrina. (2008, p.10, tradução nossa)

Percebemos que a modalidade performativa compreende os textos normativos, é um discurso que existe para produzir o efeito da obediência; a modalidade silogística compreende os textos decisórios, o discurso da decisão é organizado sobre o silogismo: premissa-conclusão; a modalidade descritiva compreende a doutrina, isto é, a filosofia do Direito.

Bocquet explica que ao contrário do jurista, que se preocupa com a natureza e a hierarquia das normas, o tradutor detém a sua atenção em critérios linguísticos e na lógica da linguagem (2008, p.23, tradução nossa). Eis a razão pela qual o professor e advogado Eduardo Bittar (2009, p.177178) ressalta que o sentido dos termos é diferenciado dentro do Direito como um todo, e completa esclarecendo que "cada um dos universos de discurso jurídico ${ }^{1}$ [tipologias] possui um processo gerativo diverso, com normas e regras de uso próprias, mas todos obedecem a um plano de formação comum".

Considerando que no interior do Direito reside uma diversidade no sentido dos termos, e embora tenham uma lógica comum, o teórico Claude Bocquet apresenta uma metodologia para a tradução jurídica que consiste em três etapas que permeiam todos os três modos.

Primeiramente, de um ponto de vista linguístico, a decodificação do discurso-fonte. A segunda etapa, de caráter não linguístico, consiste em comparar as instituições da língua-fonte e da língua-alvo, e esclarece que

\footnotetext{
${ }^{1}$ Esclarecemos que a nomenclatura utilizada - universo jurídico, instituição, tipologia - é própria de cada teórico. Enquanto Eduardo Bittar prefere universo jurídico, Sourioux et Lerat preferem instituição, e Claude Bocquet, nosso teórico, serve-se das expressões instituição e tipologia.
} 
[Comparar as instituições] É preferível do que fazer um estudo de Direito Comparado, no sentido estrito da expressão. É o momento de fazer uso dos conhecimentos gerais que o tradutor tem de seu Direito nacional. É nesta fase que acontece a essência da transferência dos sentidos. Assim como é o momento em que se produz a "inflexão do significado", isto é, a adaptação do conteúdo e de toda a mensagem destinada a ser compreendida por seu destinatário [o público alvo]. (Bocquet, 2008, p.13, tradução nossa)

Finalmente, a terceira etapa consiste na recodificação na língua alvo, uma atividade que o teórico assegura tratar-se essencialmente de onomasiologia.

Sendo assim, a partir da classificação do teórico, mas sem nos aprofundarmos nos aspectos linguísticos, discursivos e estilísticos, abordaremos algumas questões paralelas ao processo tradutório que atravessam os três modos, podendo representar problemas comumente enfrentados pelos tradutores, mas também apresentaremos soluções para casos autênticos relatados na história, cujos problemas também eram paralelos ao processo tradutório. Finalizaremos, então, com uma análise, numa perspectiva francobrasileira, da diversidade de sentidos de uma expressão cuja aplicação pode oscilar de um sistema jurídico para outro, assim como no interior de um mesmo sistema jurídico.

\section{Questões Paralelas}

A primeira discussão paralela a questões propriamente tradutórias diz respeito à linguagem jurídica; surge então o questionamento se o texto jurídico pode ser classificado como um texto técnico. Partimos da análise de Eduardo Bittar (2009) ao afirmar que o discurso jurídico "tem alguns traços elementares de sua formação diferenciada". O autor expõe que se trata de uma linguagem técnica, uma vez que se funda no histórico da vida cotidiana de uma sociedade, constrói-se na intraculturalidade, tem o caráter performativo e apresenta-se por meio de pressupostos lógico-deônticos.

A partir desta definição, no que concerne a discussão em torno de ser ou não ser técnica a tradução jurídica, Bittar (2009, p.178) acrescenta que a linguagem jurídica extrai da linguagem comum os termos e expressões necessários a seu discurso, elaborando uma metamorfose nesses signos 
linguísticos ao convertê-los em linguagem técnica, ressaltando que a prática do Direito procura determinar usos precisos para a língua natural, o que "redundou no condicionamento e na especialização de sua linguagem"; no entanto, alerta que a especificidade dos termos é diferenciada dentro do Direito como um todo.

\footnotetext{
Para a terminologia tecnicizada que compõe o dicionário jurídico, mister se faz sejam determinados precisamente os correspondentes aos "institutos jurídicos" nacionais no estrangeiro, quando da ocorrência da "tradução jurídica". Essa abordagem se privilegia em face das discussões que se podem produzir quando da aplicação do direito estrangeiro pelo juiz nacional, ou vice-versa. (op.cit., p.179, grifo nosso)
}

Da mesma forma, encontramos na obra do jurista Jean-Louis Bergel (2003) essa posição, pela qual ele esclarece que o significado dos termos é determinado por seu contexto, permitindo uma pré-interpretação do seu sentido. E acrescenta que o sentido dos termos jurídicos não está preso ao Sistema Jurídico geral, mas dependente da lógica, isto é, da ideologia de determinada instituição. Se por um lado, fechar o significado de um termo em um sentido próprio pode ser prático, por outro, existe o risco de limitar a interpretação. O jurista destaca que há uma tendência no Direito Internacional em determinar os sentidos das palavras, encerrando-os em terminologias, a fim de harmonizar as diferenças das línguas e dos sistemas jurídicos nos Atos Jurídicos Internacionais (acordos, tratados e convenções), sobretudo no tocante à União Europeia. Mas, segundo ele, esse método de trabalhar a língua é perigoso, principalmente no Direito Interno, "pois negligencia a necessária coerência de toda a ordem jurídica" (2003, p. 219, tradução nossa). Essa metodologia tende a evitar, parcialmente, os problemas causados pela polissemia, e, nesse caso, a polissemia mais perigosa não está entre a língua comum e a língua de especialidade, ela está dentro da própria língua de especialidade, nos diversos sentidos que as expressões ganham entre as mais diversas aplicações. Entretanto, vale lembrar que o Sistema Jurídico, com suas diversas instituições, forma um todo, que, apesar de todas as diferenças, está em constante interação.

Pensar a linguagem jurídica como técnica ou não técnica é analisado por Claude Bocquet (2008) por outro ângulo. Segundo o teórico, a questão 
principal não está em definir se a linguagem jurídica é ou não é técnica, embora essa necessidade esteja presente entre linguistas e tradutores. Ele defende que, "de forma pragmática, os linguistas e os tradutores devem contentar-se em enunciar uma tipologia fundada sobre a forma do discurso, ou, mais precisamente, sobre a lógica do discurso em questão". Sendo assim, ele coloca em planos diferentes a visão e o interesse do jurista e do tradutor; ao citar o jurista Gérard Cornu, Bocquet esclarece que para o Direito os discursos jurídicos são classificados segundo sua natureza. Assim, a definição importante para o tradutor reside na classificação dos textos jurídicos sustentada sobre uma tipologia tripla, na qual encontramos os modos do discurso em três aplicações: modo performativo, modo silogístico e modo descritivo.

A classificação apresentada por Bocquet serve como diretiva na execução da tarefa do tradutor, auxiliando-o a identificar e eliminar a possível polissemia existente no âmbito linguístico da terminologia e da fraseologia.

\subsection{Problemas: A Polissemia}

Sobre a polissemia referida acima, Sourioux e Lerat, jurista e linguista respectivamente, esclarecem que os termos jurídicos estão sujeitos à monossemia e à polissemia, pois quanto a esta, "trata-se de termos que pertencem, além da linguagem comum, a outras linguagens de especialidade, mas que têm uma acepção especificamente jurídica" (1975, p. 93-94, tradução nossa). Nesse contexto, deve o tradutor observar, primeiramente, o gênero textual que está sendo trabalhado; após, em se tratando de tradução especializada, deve "mergulhar nas especificidades do gênero", ou seja, deve observar as tipologias do texto jurídico, pois o caminho para acabar com a ambiguidade leva em consideração a situação de uso ou ambiente linguístico. Tal procedimento nos remete à teoria de Bocquet concernente aos três modos de discurso jurídico: performativo, silogístico e descritivo.

Ao discriminar o modo do discurso, Bocquet propõe resolver o problema da polissemia interna na linguagem jurídica. Esta é exatamente a questão desenvolvida por Bittar e Bergel ao falarem da polissemia interna ao Direito. Reproduzimos a exemplificação dada por Sourioux e Lerat (1975, p.96, tradução nossa) 
Polisemia jurídica: Entendemos assim o status semântico das palavras que têm vários sentidos no próprio interior do Direito.

'Acessão' (Accession):

a) Direito Civil: "Extensão do direito de propriedade para às coisas julgadas acessórias, as quais se unem à coisa presumida como principal". (Lexique Dalloz apud Sourioux et Lerat, 1975, tradução nossa)

b) Direito Internacional Público: "Ato pelo qual um Estado declara aderir aos compromissos acordados entre dois ou mais Estados.". (Barraine apud op. cit., 1975, tradução nossa)

Em português, no direito brasileiro, a mesma expressão - Acessão é definida por De Plácido e Silva (2009, p.51), da seguinte forma

Em suas várias acepções, acessão é:

a) É o direito conferido por lei ao proprietário de bens ou coisas sobre todos os acréscimos ou frutos produzidos, isto é, sobre tudo o que se incorpora natural ou industrialmente a essas coisas ou bens. Chama-se de acessão ao próprio acréscimo verificado ou aos frutos produzidos. [...]

b) Ato ou efeito de aceder, consentimento (ex.: acessão a um tratado).

Pelas duas explicações acima, verificamos que o tradutor deve observar a definição nos dois sistemas jurídicos: da língua fonte e da língua alvo. Este é o procedimento proposto por Bocquet como a segunda etapa do processo da tradução jurídica: a etapa da comparação das instituições de Direito.

Outro exemplo que citamos é a palavra "Convenção", que, segundo De Plácido e Silva (2009, p.382), é percebida como equivalente de Acordo, mas isso no Direito Privado (1.a), tendo o mestre citado como exemplo:"Às vezes é tido num sentido estrito, correspondente às cláusulas que são impostas no contrato de casamento". No entanto, no Direito Internacional Público (1.b), entende-se Convenção como o ajuste ou acordo sobre assuntos de interesse das Nações, de caráter não político, possuindo um sentido mais estrito do que o Tratado. Na mesma linha de raciocínio, a expressão Con- 
venção é explicada em francês por Gérard Cornu (2005, p. 239, tradução nossa) pela distinção de seus significados ao dizer que, (2.a) de forma geral, no seio dos atos jurídicos, representa qualquer acordo de vontades destinado a produzir efeito de Direito; enquanto que no Direito Internacional (2.b) sua acepção é mais específica, por designar acordos de caráter técnico. Concluímos que compreender Convenção como Acordo é uma interpretação natural; no entanto, é preciso ficar atento às especificidades de cada uso para não cair no labirinto da polissemia.

\subsection{Problemas: Terminologia e Fraseologia}

Paralelamente, encontramos a fraseologia e a terminologia. Ocorre que a terminologia não se limita ao léxico, também engloba as expressões-chave / expressions figées ou como preferem Sourioux e Lerat: Séquences figées (1975, p.31), eles se referem à sequência de elementos linguísticos intocáveis, formando um único sentido e que são usados corriqueiramente em situações idênticas. Desse modo, eles explicam que "são unidades cujo status linguístico é de um discurso repetido, ou seja, de grupos complexos que não se prestam a nenhuma modificação formal" (op. cit., tradução nossa); temos como exemplo o discurso em acordos, tratados e convenções internacionais, nos quais encontramos as expressões fraseológicas En foi de quoi = Em fé do que; entrera en vigueur le = entrerá em vigor na data de sua publicação.

O uso da terminologia e da fraseologia está de tal modo imbricado, que percebemos que a fraseologia acaba por fazer parte da terminologia, com peso de expressões-chave em certas tipologias.

Por essa razão, Gérard Cornu (2005, p. 330, tradução nossa) considera as expressões-chave como pérolas que presas ao texto fazem cintilar a lei, são mots justes -, tendo a missão de transportar valores que legitimam atos.

\subsubsection{As Siglas e os Nomes Próprios}

Nesse jogo de ambientes jurídicos, a terminologia alcança o patamar das siglas e dos nomes próprios. Surgem então outros problemas paralelos à tradução: o tamanho do texto, o que muitas vezes é determinado pelo "dono do texto", isto é, o editor ou o cliente. 
Quanto às siglas, elas são de uso cada vez mais frequente, principalmente devido à expansão da aplicação do Direito, mas também por economizarem espaço no texto. Ora, partindo da premissa de que o públicoalvo desconhece o significado da sigla na língua-fonte - exemplo: HLM = Habitation à loyer modéré [Programa de moradia popular] -, espera-se do tradutor que ele a explique, mas se o fizer incorporando a tradução ao corpo do texto (entre parênteses), o texto ficará mais extenso. Caso opte por explicar em nota de rodapé ou ao final do texto, também não atenderá a finalidade de economizar espaço; então, resta ao tradutor a opção de negociar com o dono do texto ou de deixar que o leitor busque o sentido da sigla.

Quanto aos nomes próprios, outro problema a ser encarado pelo tradutor, compreendemos pelos mesmos os nomes de órgãos, de funções, de procedimentos e de alguns outros casos. Nesse cenário, encontramos situações cuja equivalência no Sistema Jurídico da língua-alvo não existe. Se a finalidade das instituições equivalentes é a mesma, a da língua-fonte e a da língua-alvo, o mesmo não se dá com a organização judiciária, que é construída de acordo com cada cultura. Eis por que esse problema tradutório é muito frequente na tradução jurídica do Direito Processual. Assim sendo, por exemplo, encontramos na França o Juge d'Instruction, que não existe no Brasil; essa função é exercida aqui, parcialmente, pela Autoridade Policial, parcialmente pelo Ministério Público, este, após receber os autos do inquérito policial fará ou não a Denúncia, dando início à Ação Penal. Na França, o Juge d'Instruction é designado para a missão de proceder a toda a fase de investigação (colher provas, expedir mandados, fazer interrogatórios, acareação, etc.) até a fase final, que consiste na instauração da Ação Penal (mise en cause) ou com o pedido de arquivamento por falta de provas/ uma ordenança de non-lieu. Essas não são as únicas situações, outras existem e precisam de solução.

Refletindo ainda sobre os nomes próprios, verificamos que se no Brasil o juiz da Corte Suprema recebe o título de ministro, o mesmo título dado a um membro da equipe do governo federal responsável por um ministério, o mesmo não ocorre na França; lá, o membro da equipe do governo da República responsável por um ministério recebe o título de ministre, 
enquanto que o juiz da Cour Suprême recebe o título de Conseiller. Não se trata apenas de uma questão de terminologia, é preciso ler o texto da lei para saber se as atribuições dadas pela lei ao juiz da Corte Máxima são as mesmas. Igualmente, ocorre o entendimento do que é a Corte Máxima. Em primeiro lugar, como disse Bocquet (2009, p.13, tradução nossa), "nesse momento o tradutor tem de fazer uso do seu conhecimento sobre o assunto - do seu conhecimento do Direito Nacional". A partir de então, deve conhecer o Sistema Jurídico na língua-fonte. Partindo da premissa de que o Juge d'Instruction não tem equivalência, e de que as instituições são comparáveis e não idênticas. Então, qual seria a melhor solução tradutória? Para essa questão, contamos com a explicação de Malcolm Harvey (2009), que nos apresenta algumas possibilidades de trabalho.

\subsection{Soluções}

Procuramos abordar, neste momento, teorias e relatos que apontam soluções tradutórias para as situações que podem levar o tradutor "a caminhar sem cessar por um caminho estreito e deslizante que não é de sua escolha, tendo, às vezes, que se jogar de lado para evitar o precipício" (D'Alembert, vol.4 p.42, tradução nossa), e que impõem um conhecimento extralinguístico da parte do tradutor para evitar o precipício.

\subsubsection{Equivalência cultural e tradução etnocêntrica}

Inicialmente, observamos a "equivalência cultural", que consiste em servir-se da analogia procurando um equivalente na cultura alvo. Entretanto, o professor e tradutor Malcolm Harvey deixa claro que "existem riscos de imprecisão apesar da semelhança formal, essa forma aborda realidades muito diferentes". Ressaltamos que o exemplo dado por Harvey foi: "juge d'instruction" vertido para o inglês; por essa razão, ele alerta que a "equivalência cultural", classificada como tradução etnocêntrica, apresenta muitos perigos e que "deve ser trabalhada com precaução em uma tradução destinada aos especialistas da área". E completa

Levada ao extremo, a vontade de explicar tudo por analogia por meio de uma realidade já conhecida apaga a diferença, criando a impressão de uma cultura internacionalizada e homogênea. Essa abordagem não valori- 
za nem mesmo o tradutor, pois ao invés de ser uma ponte entre duas culturas, ela apaga uma em proveito de outra. (2009, p.82, tradução nossa)

\subsubsection{Equivalência formal: Tradução Identificadora}

Por outro lado, caso o tradutor decida por um caminho imediatamente oposto, ele poderá adotar a "equivalência formal", na qual, segundo o professor Harvey, existe o risco do decalque. Esse método de tradução é decididamente orientado para a cultura-fonte, assumindo e acentuando, em alguns casos, as diferenças (Harvey, op. cit., p.83). O decalque é um dos procedimentos técnicos da tradução enumerados por Vinay e Darbelnet (1977 apud Barbosa, 2004, p.23-26) no eixo da tradução direta; para eles, o decalque é quase um empréstimo, sendo que o decalque abrange um sintagma no lugar de apenas uma palavra. Pode ser classificado em "decalque de expressão" quando utiliza as palavras existentes na língua alvo, respeitando também sua estrutura sintática; ou em "decalque de estrutura", quando utiliza as palavras da língua alvo, embora em construções sintáticas da língua fonte" (Barbosa, 2004, p.26-27). Esse recurso é proposto quando da total impossibilidade de tradução, como foi dito pelo professor e pesquisador José Lambert ${ }^{2}$ : "A 'não-tradução' faz parte da tradução. É o decalque".

\subsubsection{Tradução descritiva}

Em seguida, Harvey apresenta o método da tradução descritiva, consistindo em uma explicação concisa e com o uso de termos genéricos, não específicos a nenhuma cultura. Ocorre que essa opção não satisfaz o especialista da área, que deverá buscar explicações. Podemos visualizar aqui o uso dos hiperônimos e dos hipônimos como recurso para os problemas tradutórios, como ensina Michel Ballard (2003) sobre a relação "hipero-hiponímica": "É gerada pela constatação de um déficit lexical no âmbito da contextualização, necessitando de uma intervenção maior do tradutor na medida em que sua participação solicita criatividade" (2003, p. 255, tradução nossa). A contribuição do tradutor pode ser desencadeada, entre outros fatores, pela necessidade de clareza, é antes de tudo um ato de consciência. Assim, no lugar de usar um decalque para traduzir "Cour de Cassation" por "Corte de

\footnotetext{
${ }^{2}$ Lambert, J. (Conferência de José Lambert, Faculdade de Letras - UFRJ, 29 de abril de 2009).
} 
Cassação", o tradutor optaria por seu hiperônimo "Corte Suprema da França nas jurisdições civis e penais da ordem judiciária" (Guinchard, 2012, p.251, tradução nossa).

\subsubsection{Transcrição}

Por último, Harvey nos fala da transcrição. Esta adota o uso de glosas para resolver as questões tradutórias. A transcrição apresenta como aspecto positivo a impossibilidade de criar ambiguidade, apresentando a expressão tal como é, entretanto com explicações em glosas, seja no corpo do texto, entre parênteses ou em nota de rodapé. Nesse caso, no exemplo dado acima - Cour de Cassation -, o tradutor adotaria: "Corte de Cassação (A Corte de Cassação, mais alta instância do Poder Judiciário Francês nas jurisdições civis e penais da ordem judiciária francesa, corresponde ao Supremo Tribunal Federal, no Brasil). Entretanto, essas glosas no corpo do texto podem interromper a leitura, enquanto que as glosas localizadas no rodapé ou no final do texto não causam interrupções obrigatórias, mas orientam o leitor, sobretudo quando se trata de alguém iniciado na matéria. É um método que deixa claro a diferença, respeitando o Outro. Dessa forma, o tradutor se faz presente, "ele sai da sombra e intervém diretamente no texto para guiar o leitor" (Harvey, 2009, p.84).

\subsubsection{Intervenção do Tradutor: Explicadora}

Essa intervenção é justificada por Bocquet quando analisa as decisões tradutórias aplicadas por Aubry e Rau, ainda no século XIX (1837). Nessa época, dois juristas alsacianos foram responsáveis pela tradução do alemão para o francês da obra doutrinária de autoria de Zachariae: um comentário ao Código Civil Napoleônico, o qual houvera sido traduzido do francês para o alemão acompanhado de comentários ${ }^{3}$. Vale lembrar que o Código Civil Napoleônico entrou em vigor em 1804. Considerado como a aurora jurídica da modernidade, a obra de Napoleão foi analisada por Zachariae como

\footnotetext{
3 Trata-se do Cours de Droit Civil Français, de Zachariae, jurista, professor e um dos mestres mais ilustres de universidades alemãs (Bocquet, 2008, p.75, tradução nossa).
} 


\begin{abstract}
Um instrumento científico privilegiado, visto se tratar do primeiro código moderno e pelo fato de nos apresentar a solução para praticamente todos os problemas jurídicos da existência, seja em relação à família, ao contrato ou à propriedade.

E o Conde Zachariae vai analisar o texto que ele considera quase perfeito. (Bocquet, 2008, p. 71, tradução nossa)
\end{abstract}

No entanto, nos limites do "quase perfeito", a obra estava muito presa às questões culturais da sociedade francesa napoleônica. Eis por que Zachariae empreendeu certas modificações obedecendo a certos critérios científicos.

Esta será, aliás, a lógica de apresentação de todos os códigos modernos adotados posteriormente: Código Civil italiano de 1860, o Código Civil alemão de 1900 e o Código Civil suíço de 1912. Não seria um exagero dizer que essa modificação foi a grande contribuição científica de Zachariae. (Bocquet, 2008, p. 72, tradução nossa)

Ao retornar para a língua francesa, o Código Napoleônico passou por um processo de tradução cujos autores - Aubry e Rau - depararam-se com um dilema, o qual consistia em não fazer uma tradução literal, mesmo sendo preciso agradar o público-alvo francês (orgulhoso do Código Napoleônico). Nesse momento, vemos a tradução à mercê dos interesses políticos e econômicos. Dessa forma, inicialmente tomaram a decisão de adotar as glosas. O método das notas explicativas consistia em apresentar o texto original em duas ou três linhas em destaque e no alto da página, seguido de notas, em caracteres pequenos, ocupando aproximadamente cinquenta linhas, explicando o texto original. Ora, essa metodologia das notas explicativas acarretaria um problema maior, e extremamente atual, deixaria a obra muito volumosa e, consequentemente com um valor muito elevado. Por esse motivo, pensaram em uma segunda opção de tradução ${ }^{4}$ : decidiram por uma adaptação ao gosto e às necessidades políticas do público-alvo francês [...] É o preceito das "Belles Infidèles": agradar seu público, e não chocá-lo (op. cit., p. 73). Porém, era preciso explicar que o contexto político-social do

${ }^{4}$ Bocquet, Traduction Juridique et Approppriation par le Traducteur. L'Afffaire Zachariae, Aubry et Rau. Disponível em: www.tradulex.org//Actes2000/bocquet.pdf. Acesso em 11 nov. 2010. 
momento da obra traduzida era bem diferente daquele da obra original, levando em conta as mudanças com as "novas ciências" que vinham ocorrendo na sociedade, quer dizer, tratava-se do "Positivismo Jurídico" do século XIX. A terceira possibilidade consistia em acrescentar à anterior um prefácio justificando as decisões tradutórias, deixando entrever o original - o Outro -, respeitando, assim, a diversidade de línguas, de culturas e de culturas Jurídicas.

Assim, Bocquet comenta: "É muito difícil para uma personalidade forte, o tradutor, ficar como um intérprete passivo da doutrina de alguém. Fatalmente, a originalidade do tradutor se afirma diante das ideias do autor" (2008, p.75, tradução nossa).

Ao final, Aubry e Rau decidiram por elaborar um trabalho a baixo custo, uma tradução "naturalizadora", adaptada ao gosto e às necessidades do público alvo. Entretanto, fizeram uso de um prefácio explicativo de suas opções de tradução e do contexto histórico do momento cultural da elaboração do código.

Após breve exposição dos prós e dos contras de cinco metodologias de tradução propostas para os casos de "problemas tradutórios", que podemos resumir em: naturalizadora (etnocêntrica), identificadora (literal/ decalque), descritiva (hiperônimo), transcrição (com explicação) e explicadora com glosas (comentada), percebemos que o neologismo, que será apresentado a seguir, não é uma opção adotada pelos estudiosos aqui expostos.

\subsubsection{Neologismo}

Embora o neologismo tenha sido um recurso tradutório adotado ao longo da história, provocando fortes correntes tanto de adeptos quanto de opositores, nos tempos modernos ele não é completamente rechaçado, pois alguns o veem pelo prisma da globalização. Dessa forma, sobre os neologismos, Cornu faz uma observação, não como solução tradutória, mas como um processo de evolução da língua, que pode acontecer eventualmente na linguagem do Direito. Diz ele: 
termos jurídicos conserva sua forma não por uma questão de respeito à tradição, mas pela necessidade de seu sentido de precisão $(2005$, p. 317, tradução nossa)

Apesar das soluções aqui propostas, em se tratando de Tradução Jurídica, mormente de Discurso Legislativo, fica a advertência lançada por Gérard Cornu (op. cit. p.318, tradução nossa): "Sempre que um termo técnico (próprio da terminologia jurídica) for o único capaz de restituir com precisão a ideia do Legislador, ele deve prevalecer. Na inexistência de um equivalente, decide-se por mantê-lo".

Enfim, a partir do exposto, encerramos esta análise teórica recordando os critérios tradutórios defendidos pelo teórico Claude Bocquet, em que a tradução jurídica consiste em três etapas: a primeira corresponde a um trabalho linguístico de decodificação do discurso; na segunda, o discurso é atravessado por seu contexto jurídico. Neste momento, o tradutor trará à tona o conhecimento que detém do seu Direito, aquele cujas normas regem a sua vida e a de seus concidadãos. Por fim, vem a terceira etapa: a recodificação linguística em outro idioma, adaptando o texto-fonte a outro Sistema Jurídico (língua-alvo). É uma trama complexa que justifica o questionamento feito pelo professor Jacques Pélage sobre a possibilidade de uma tradução produzir o mesmo resultado discursivo e jurídico daquele produzido por seu discurso de origem; ou seja, sobre a Efetividade da tradução jurídica.

\section{Estudo de Caso}

Relembramos as palavras de Sourioux e Lerat: "No interior de uma mesma linguagem jurídica, um termo pode estar revestido de diferentes significados".

A problemática abordada pelo jurista e pelo linguista nos aponta que certo termo ganha sentidos diferentes não só na passagem de uma língua para a outra e de um sistema jurídico para outro, mas também no interior de um mesmo sistema jurídico, trata-se da polissemia.

Nesse sentido, Gérard Cornu - jurista, professor de Direito e pesquisador da lexicografia jurídica -, em seu artigo As definições na lei (In: GÉMAR, 1982) questiona se cabe ao poder público e suas instituições o ris- 
co de estipular definições e romper o sentido comum e jurídico das palavras. Ao interferir no(s) sentido(s) de expressões linguísticas, as instituições do Estado (Legislativo e Judiciário), flexionam o sentido natural da linguagem, fechando seu(s) sentido(s) em definições, simplificando suas interpretações, privilegiando um sentido dentre outros. Assim, ele esclarece que

O fato é que muitas palavras têm sentidos diversos e que algumas não têm um significado evidente. A polissemia e a ambiguidade são fenômenos irredutíveis da linguagem, incidentes ou acidentes da comunicação linguística. Entre outras intervenções estatais em matéria de linguagem, a definição legal poderia ter pelo menos a função, e justificação, de dissipar o equívoco e a obscuridade. (op. cit., p.18. Tradução nossa).

As críticas feitas por Cornu sobre a institucionalização das "definições" encontram um "porém", exposto pelo próprio autor quando cita o modelo aristotélico "destinado a extrair 'o essencial da essência de um objeto': a definição nesse caso tende, por aproximações sucessivas, agregar o objeto a um gênero, distinguindo-o, depois, por seus caracteres próprios, das outras espécies do gênero" (Cornu, In: Gémar, 1982, p.18, tradução nossa). Este princípio procura facilitar a interpretação dos termos e dos atos das línguas de especialidade. O jurista acrescenta que essa situação também atinge a tradução, explicando que a tradução de especialidade tem um público alvo iniciado na matéria. Isto possibilita que o texto traduzido seja submetido à avaliação do público alvo, o qual tem possibilidades de detectar quando uma escolha é considerável razoável ou não.

Eis por que Bocquet defende que, na fase intermediária do processo de tradução, o profissional deve servir-se dos conhecimentos que tem de sua cultura. Tratando-se da tradução de especialidade, o tradutor fará uso do conhecimento sobre matéria tratada da forma como ela existe em sua cultura e língua maternas para, assim, ter condições de, contrapondo com o texto original, reconstruí-lo na língua/ cultura de tradução.

Expomos, em seguida, a título de exemplo, a tradução de um ato normativo: "Medida Provisória"; analisaremos as possibilidades e impossibilidades tradutórias, considerando as definições para o ato, constantes nas leis francesa e brasileira, assim como a equivalência, ou não, com a "Mesure Provisoire" do sistema judiciário francês. 
MEDIDA PROVISÓRIA / MESURE PROVISOIRE

\begin{tabular}{|c|c|}
\hline Direito Brasileiro & Direito Francês \\
\hline "Poder Executivo e Legislativo" & "Poder Executivo e Legislativo" \\
\hline $\begin{array}{l}\text { Medida Provisória: Espécie Normativa. Tendo } \\
\text { força de lei, é adotada pelo Chefe do Poder } \\
\text { Executivo em caso de relevância e de urgência, } \\
\text { devendo ser levada imediatamente ao conhe- } \\
\text { cimento do Congresso Nacional, que a analisa- } \\
\text { rá e poderá convertê-la ou não em lei. (De } \\
\text { Plácido e Silva) } \\
\text { Prevista na Constituição Federal, arts. } 59,62,84\end{array}$ & $\begin{array}{l}\text { Ordonnance: Em Direito Constitucional } \\
\text { Ato exercido pelo Governo, com autoriza- } \\
\text { ção do Parlamento, em matérias que são do } \\
\text { domínio da Lei, com limites de matéria e } \\
\text { de tempo de validade. Antes da ratificação } \\
\text { pelo Parlamento, a ordenança tem valor de } \\
\text { regulamento; após a ratificação, ganha } \\
\text { valor de lei. } \\
\text { (Lexique des termes juridique) }^{6} \\
\text { Prevista na Constituição de } 1958 \text {, Art. } 38\end{array}$ \\
\hline "Poder Judiciário" & "Poder Judiciário" \\
\hline $\begin{array}{l}\text { Medida cautelar - LIMINAR (art. } 796 \text { e se- } \\
\text { guintes CPC) }\end{array}$ & $\begin{array}{l}\text { Mesure Provisoire: } \\
\text { 1- Cornu }\end{array}$ \\
\hline $\begin{array}{l}\text { Em sentido amplo, entende-se, na terminolo- } \\
\text { gia processual, todo e qualquer ato forense ou } \\
\text { processo intentado por alguém, em Justiça } \\
\text { para prevenir, conservar ou defender direitos. } \\
\text { Em quaisquer dos casos, é um ato de preven- } \\
\text { ção ou ato de precaução promovido pelo Judi- } \\
\text { ciário. (De Plácido e Silva) }\end{array}$ & $\begin{array}{l}\text { Medida tomada no curso de um processo a } \\
\text { fim de regular momentaneamente uma } \\
\text { situação urgente, esperando uma decisão } \\
\text { definitiva. Ex. pensão de alimentos, seques- } \\
\text { tro de um bem em litígio, etc. }{ }^{8} \\
\text { 2- Thales Morais }{ }^{9} \\
\text { Medidas provisórias em matéria processu- } \\
\text { al. }\end{array}$ \\
\hline
\end{tabular}

Como observamos, os significados podem ser diferentes dependendo do contexto, mas a substância linguística pode continuar a mesma, no caso de nosso exemplo vem a ser "Medida Provisória" / "Mesure Provisoire".

Eis por que Bocquet (2008, p.102) alerta

\footnotetext{
${ }^{5}$ De Plácido e Silva, 2009, p. 905.

${ }^{6}$ Lexique Juridique, 2012. Tradução nossa.

7 De Plácido e Silva, 2009.

${ }^{8}$ Cornu, 2009, p.588. Tradução nossa.

${ }^{9}$ Thales de Moraes. Introdução ao Direito Francês. V.1, 2009, p.634.
} 


\begin{abstract}
Não há dúvida de que o Direito de cada país produziu uma terminologia rígida, cujo domínio é incondicionalmente necessário ao tradutor. No entanto, toda a documentação bilíngue existente parte da premissa de que é possível, com uma pequena referência às instituições comparadas, criar um sistema de correspondência biunívoca.
\end{abstract}

Ou seja, trata-se de um sistema de correspondência que associa, a cada um dos elementos de um conjunto, um único elemento de outro conjunto, e vice-versa.

As definições institucionalizadas que privilegiam um sentido dentre outros têm a finalidade de evitar o risco da polissemia e da ambiguidade, que Cornu diz serem fenômenos irredutíveis da linguagem. Em se tratando das línguas de especialidade, a precisão das definições viabiliza a efetividade do discurso, da mensagem, embora usadas com cautela. Além do que, serve de ferramenta do processo tradutório, possibilitando a execução das três etapas defendidas por Bocquet.

Dessa forma, mais uma vez enfatizamos que para nosso teórico Claude Bocquet a metodologia apropriada para a tradução de especialidade deve estar estruturada sobre os três eixos que ele defende: decodificação do discurso-fonte, comparação das instituições do país da língua-fonte com as do país de língua-alvo e recodificação da mensagem jurídica concebida para outro sistema jurídico, no discurso-alvo.

\title{
4. Conclusão
}

Traduzir é uma tarefa tão útil quanto complicada. De imensa responsabilidade, sobretudo quando se trata de Tradução Especializada, uma vez que o trabalho requer do tradutor um conhecimento geral que ultrapassa o conhecimento das duas línguas trabalhadas.

No entanto, há um aspecto positivo que auxilia a "tarefa do tradutor": a tradução especializada é feita para um público alvo conhecedor da matéria. Por esse ângulo, percebemos que a compreensão e a efetividade do texto traduzido não dependem, precisamente, de pequenas escolhas feitas pelo tradutor, pois o público alvo, aquele que conhece a matéria, irá compreendê-lo pelo contexto geral. No caso de uma escolha destoante, fica ní- 
tida a descontextualização. Este é um caso evidente de que o tradutor não "mergulhou nas especificidades do gênero", o que leva o público alvo a identificar a escolha indevida que torna a mensagem ilegítima. Logo, o tradutor não operou devidamente as três fases do processo tradutório das quais fala Bocquet.

Pelo exposto neste trabalho, notamos que a tradução especializada é sempre uma armadilha para o tradutor, já que a perfeição é inalcançável. Por esse motivo, o que está ao alcance do tradutor é a busca pelo "quase a mesma coisa". Na busca quase insana pela perfeição, o tradutor, sujeitoreceptor do discurso original que se transforma em sujeito-enunciador do discurso final, representa uma ponte linguística, permitindo que os dois pontos separados pela língua possam encontrar um lugar comum, onde a ideia de um possa ser expressa na língua do outro.

A tarefa do tradutor é simbolizada por uma aliança que representa a união entre os povos, pois a tradução é a única forma de superar o abismo linguístico e cultural e de viabilizar a "União na Diversidade".

\section{Referências}

BALLARD. M. Entre Choix et Créativité: Balisage d'un parcours de traduction. In: BALLARD, M; KADAFI, A. E. (Org.). Traductologie, Linguistique et Traduction. Arras Artois Presses Université, 2003.

BARBOSA, H. Procedimentos Técnicos da Tradução. 2ed. São Paulo: Pontes, 2004.

BERGEL, J.-L. Méthode du Droit. Théorie Générale du Droit. $4^{\mathrm{a}}$ ed. Paris: Dalloz, 2003.

BITTAR, E. Linguagem Jurídica. 4a ed. São Paulo: Saraiva, 2009.

BOCQUET. C. La Traduction Juridique: Fondement et Méthode. Bruxelles: De Boeck, 2008.

Traduction Juridique et Approppriation par le Traducteur.

L'Afffaire Zachariae, Aubry e Rau. Disponível em: www.tradulex.org//Actes2000/bocquet .pdf. Acesso em 11 nov. 2010.

CORNU, G. Linguistique Juridique. $3^{a}$ ed., Paris: Montchrestien, 2005. . Vocabulaire Juridique. $8^{\mathrm{a}}$ ed., $4^{\mathrm{a}}$ tiragem. Paris, ed: PUF, 2009.

Les définitions dans la loi. In: GÉMAR, J.-C. (Org). Langage $d u$

Droit et Traduction - Essais de jurilinguistique. Montréal: Linguatech; Conseil de la langue française, 1982. 
COSTA, T. M. (coord.). Introdução ao Direito Francês. V. 1. Curitiba, ed: Juruá, 2009.

D'ALEMBERT, J. R. CEuvres de D'Alembert, vol. 4. p. 42. Observations sur l'Art de Traduire.

Disponível em: " https://books.google.fr/books?id=_F07AAAAYAAJ". Acesso em 6 ago. 2016.

GUEDES, R. M. Os Meandros da Tradução Jurídica numa Perspectiva FrancoBrasileira. Jundiaí: Paco Editorial, 2014.

GUINCHARD (Org.), S. Lexique des termes Juridiques. 19. ed., Paris, ed: Dalloz, 2012.

HARVEY, M. Le traducteur juridique face à la différence. Traduire, n. 221, dez. 2009.

SILVA, De P. e. Vocabulário Jurídico. $28^{a}$ ed. Atualizado por Nagib Slaibi Filho e Gláucia Carvalho. Rio de Janeiro: Forense, 2009.

SOURIOUX, J.-L.; LERAT, P. Le Langage du Droit. Paris: PUF, 1975. . L'Analyse de Texte. Méthode Générale et Applications au Droit. 5. ed. Paris: Dalloz, 2005.

Resumo: Este artigo pretende explorar, sem esgotar, os problemas paralelos aos problemas centrais da Tradução Especializada no contexto da Tradução Jurídica, no âmbito franco-brasileiro, assim como as soluções propostas na literatura e em casos autênticos registrados na história. Para tanto, contamos com o suporte teórico de Claude Bocquet (2008), cuja teoria consiste numa metodologia estruturada sobre três pilares: decodificaçãoção do discurso fonte, comparação das instituições dos dois países em questão, recodificação no discurso alvo. Ao final, expomos um estudo de caso sobre a polissemia na linguagem jurídica e os riscos da terminologia biunívoca.

Palavras-chave: tradução, gênero, tipologia, instituição.

Resumé: Cet article a le but d'exposer, sans épuiser, les problèmes parallèles aux problèmes noyaux de la Traduction des textes de spécialité dans le contexte de la Traduction Juridique franco-brésilienne, de même que les solutions proposées dans la littérature et dans des cas authentiques enregistrés dans l'histoire. Pour cela, nous comptons sur le soutien théorique de Claude Bocquet (2008), dont le travail nous présente sa théorie bâtie d'une méthodologie structurée sur trois piliers : le décryptage du discours-source, 
GUEDES, Tradução especializada: Um mergulho nas especificidades do gênero jurídico

la comparaison des institutions des deux pays concernés, le recryptage du discours-cible. À la fin, nous présentons une étude de cas sur la polysémie du langage juridique et les risques de la terminologie biunivoque.

Mots-clés: traduction, genre, typologie, institution. 